\title{
Nasal Spray Use Technique Among Patients Attending the Out-Patient Department of a Tertiary Care Hospital, Gandaki Province, Nepal
}

This article was published in the following Dove Press journal: Integrated Pharmacy Research and Practice

\section{Binita KC Gulam Muhammad Khan Niranjan Shrestha}

School of Health and Allied Sciences, Pokhara University, Kaski, Nepal
Correspondence: Binita KC School of Health and Allied Sciences, Pokhara University, Kaski, Nepal Tel +9779846347207

Email kcbinita05@gmail.com
Background: Nasal sprays are used to deliver the medications locally to the nasal cavity. The majority of patients have been observed to perform nasal spray use techniques inadequately. This study was conducted to evaluate the impact of the intervention on nasal spray use technique.

Methods: This was a prospective pre- and post-interventional study to evaluate the nasal spray use technique among the subjects with the help of nasal spray checklist. A standardized WHO nasal spray checklist was used on the study conducted in Manipal Teaching Hospital, Pokhara, Nepal from July to October 2019. Subjects were asked to demonstrate the technique and a scoring system was applied before and after the intervention by the researcher. The total score of the intervention technique ranges from 0 to 11 . After evaluation of the technique at the first visit, subjects were provided with an informative leaflet having all the steps to be followed to use the spray and the technique was re-evaluated after 10 days. Results: A total of 81 subjects (51.9\% male and $48.1 \%$ female) participated in the study. The average duration of nasal drug use was 15 days. The overall mean \pm SD score was 4.31 \pm 1.625 before intervention and $9.84 \pm 1.699$ after intervention. After the intervention, the percentage of subjects using the nasal spray correctly increased by $50.27 \%$. Wilcoxon signed rank test showed intervention on nasal spray use technique was effective $(p=0.0001)$.

Conclusion: The nasal spray use technique was poor among the subjects before the intervention. The intervention was substantially effective in improving the technique to use the nasal spray. Regular assessment and reinforcement of correct technique by health professionals will improve the proper use technique of nasal spray, hence increasing the effectiveness of the therapy.

Keywords: nasal spray, pharmacist-led intervention, impact, allergic rhinitis

\section{Introduction}

Rhinitis is inflammation of the membrane lining the nose, characterized by nasal congestion, rhinorrhea, sneezing, itching of the nose and/or post-nasal drainage ${ }^{1}$ classified as allergic or non-allergic. ${ }^{2}$ Allergic rhinitis (AR) occurs when an allergen is a trigger for the nasal symptoms while non-allergic rhinitis (NAR) occurs when obstruction and rhinorrhea occur. Both allergic and non-allergic rhinitis are highly prevalent and have a significant effect on the quality of life (QOL). ${ }^{3}$

Allergic rhinitis affects about $10-20 \%$ of the world population. ${ }^{4}$ In Europe and the US, the prevalence of allergic rhinitis was estimated to be $22 \%$. ${ }^{5,6}$ Management of $\mathrm{AR}$ is important for preventing potential complications. The treatment options 
include allergen avoidance, pharmacotherapy and immunotherapy. Treatment guidelines support that the use of intranasal corticosteroid sprays (INCS) as the first-line therapy for AR. ${ }^{1,7}$ Topical intranasal steroid sprays are highly effective for patients with allergic rhinitis, rhinosinusitis $^{8,9}$ and nasal polyposis $(\mathrm{NP})^{10}$ and improve the quality of life. They act locally on the nasal mucosa and most available preparations are effective with a oncedaily dose, which reflects safety, efficacy and convenience. ${ }^{11}$ The intranasal steroid sprays have minimal side effects with one common side effect being epistaxis which is usually minor and self-limited which may be the direct effect of corticosteroid, preservative, the pressure of application, or technique used. ${ }^{12}$

There exists non-adherence to the self-administered medications due to poor instructions, poor patient-provider relationships and patients' disagreement with need for treatment. ${ }^{13}$ Many users use the inhalers incorrectly even after the instructions are provided. ${ }^{14}$ The nasal sprays are the drugs for self-medication which become risky when the patients are poorly educated regarding their correct use. Moreover, there is a lack of health professionals who could provide proper guidance to the user. ${ }^{4}$ Because many mistakes are still being made by asthmatic patients during inhalation of lung medication, it is important to gain insight into current techniques used to administer INCS. It may be expected that the administration technique may affect the efficacy, the occurrence of AEs and compliance. ${ }^{15}$ This study aimed to evaluate the impact of a pharmacist-led intervention on nasal spray use technique.

\section{Materials and Methods}

The study was a prospective pre-post interventional study conducted in the medication counseling center of Manipal Teaching Hospital (MTH), Pokhara, Nepal from July to October 2019. Ethical approval (Ref no. 7/076/077) was obtained from Institutional Review Committee (IRC)/ Pokhara University Research Center (PURC) and data collection approval (Ref no. 1296) was obtained from Manipal College of Medical Sciences, Pokhara, Nepal. The study was conducted according to the principles of Helsinki Declaration. Participants were informed about the study objective and informed written consent was obtained from all the participants before enrolling them into the study. All the out-patients above 18 years prescribed with any kind of nasal spray were included in the study. Those patients with serious illness, visual, hearing and communication problems, patients who were unwilling to give a consent and those who could perform all 11 steps correctly were the exclusion criteria. The subjects were interviewed for their demographic details followed by a demonstration of the nasal spray use technique. WHO nasal spray checklist ${ }^{20}$ was used to assess the nasal spray use technique which consists of 11 steps (Table 1). Each correct step was assigned 1 and the incorrect or missed step was assigned 0 . Hence, the maximum score obtained was 11 . The total score of greater than 9 was considered as good, 7 to 8 was considered as moderate and less than 6 was considered as poor. Subjects with score 11 were considered to be using the correct nasal spray technique and excluded from the intervention. The immediate intervention was provided to those who failed to demonstrate the correct technique. The intervention comprised individualized education and training on the correct use of nasal spray by a registered pharmacist with the help of a pictorial leaflet in the local language. The approximate time spent for immediate intervention is 10 minutes for an individual subject. The leaflet was prepared concerning the WHO checklist which was translated and validated by a group of pharmacists and Nepali language expertise. Since most subjects were called for follow-up after 10 days and the average duration of nasal spray use was 15 days, the subjects were followed after ten days and the nasal spray use technique was reassessed. All the subjects were evaluated and no one lost due to followup.

Data were entered and analyzed using Statistical Package for Social Sciences (SPSS) 20. Descriptive statistics like frequency, percentage, mean and standard deviation were used to present the socio-demographic characteristics and score of the nasal spray use technique. The numeric data were checked for normality by using Shapiro-Wilk test. Wilcoxon signed-rank test was used to evaluate the effectiveness of a pharmacist-led intervention. A Chi-square test was used to determine the association between various factors and spray use techniques. A p-value $<0.05$ was considered significant.

\section{Results}

Among the subjects prescribed with nasal spray, none of the subjects scored 11 on the tool used, thus all of them were taken for the study. The demographic characteristic of 81 subjects included in the study is shown in Table 2. Males were predominant (51.9\%) and the majority were young adults (18-35 years).

The frequency and percentage of subjects performing each step correctly in a different time period using 
Table I Frequency and Percentage of Subjects Performing Each Step Correctly

\begin{tabular}{|c|c|c|c|}
\hline \multirow[t]{2}{*}{ Nasal Spray Checklist } & $\begin{array}{l}\text { Pre- } \\
\text { Intervention }\end{array}$ & $\begin{array}{l}\text { Immediate } \\
\text { Intervention }\end{array}$ & $\begin{array}{l}\text { Post- } \\
\text { Intervention }\end{array}$ \\
\hline & n (\%) & n (\%) & n (\%) \\
\hline I. Blow the nose & $19(23.50)$ & $78(96.30)$ & $69(85.20)$ \\
\hline 2. Sit with head slightly tilted forward & $32(39.50)$ & $81(100)$ & $79(97.50)$ \\
\hline 3. Shake the spray & $73(90.10)$ & $81(100)$ & $80(98.80)$ \\
\hline 4. Insert the to tip into the nostril & $79(69)$ & $81(100)$ & $79(97.50)$ \\
\hline 5. Close the nostril and mouth & $67(82.70)$ & $81(100)$ & $80(98.80)$ \\
\hline 6. Spray by squeezing the vial and sniff slowly & $69(85.20)$ & $81(100)$ & $81(100)$ \\
\hline $\begin{array}{l}\text { 7. Remove the tip from the nose and bend the head forward strongly (head } \\
\text { between the knees) }\end{array}$ & $0(0)$ & $76(93.80)$ & $61(75.30)$ \\
\hline 8. Sit up after few seconds & $0(0)$ & $76(93.80)$ & $62(76.50)$ \\
\hline 9. Breathe through the mouth & $9(11.10)$ & $79(97.50)$ & $77(95.10)$ \\
\hline 10. Repeat the procedure for other nostril if necessary & $8(9.90)$ & $77(95.10)$ & $70(86.40)$ \\
\hline II. Clean the tip & $3(3.70)$ & $78(96.30)$ & $59(72.80)$ \\
\hline
\end{tabular}

Table 2 Demographic Characteristic of Subjects

\begin{tabular}{|l|l|l|}
\hline Variables & Category & $\mathbf{n}(\%)$ \\
\hline Age in years & $18-35$ & $49(60.5)$ \\
& $36-55$ & $26(32.1)$ \\
& Above 55 & $6(7.4)$ \\
\hline Gender & Male & $42(51.9)$ \\
& Female & $39(48.1)$ \\
\hline \multirow{2}{*}{ Marital status } & Married & $59(72.8)$ \\
& Unmarried & $22(27.2)$ \\
\hline \multirow{2}{*}{ Education } & Informal & $5(6.2)$ \\
& Basic & $16(19.8)$ \\
& Secondary & $31(38.3)$ \\
& Undergraduate and above & $29(35.8)$ \\
\hline \multirow{2}{*}{ Occupation } & House maker & $21(25.9)$ \\
& Agriculture & $14(17.3)$ \\
& Businessman & $11(13.6)$ \\
& Government employ & $6(7.4)$ \\
& Self employed & $5(6.2)$ \\
& Teacher & $10(12.3)$ \\
& Student & $12(14.8)$ \\
& Labor & $2(2.5)$ \\
\hline
\end{tabular}

a standardized WHO nasal spray checklist is presented in Table 1.

The mean scores of nasal spray use technique of pre, immediate and post-intervention were $4.31 \pm 1.625,10.73$ \pm 0.881 and $9.84 \pm 1.669$, respectively.

A total of 79 subjects had a post score higher than the pre score while two patients had an equal score before and after the intervention. The impact of the intervention was evaluated using Wilcoxon signed-rank test which showed the pharmacist-led intervention on the nasal spray technique was effective ( $p=0.0001$ ). After the intervention, the percentage of subjects using the nasal spray correctly increased by $50.27 \%$.

A Chi-square test was used to see the association of various socio-demographic variables and intranasal spray technique (Table 3). Respondents' education was found to be significantly associated with the spray technique.

\section{Discussion}

This study was conducted to investigate the technique used to administer the nasal spray according to the available WHO checklist. In our study, majority of subjects were active young adult groups (age 18-35 years) followed by middle-aged adults. Based on occupation, the majority of subjects were house makers $(25.9 \%)$ and agriculture $(17.3 \%)$ and student (14.8\%). The review of Chong and Chew suggests that people with more computer usage, higher education, higher stress level and lesser sleeping time were presented with higher AR susceptibility ${ }^{16}$ which may lead to the use of nasal spray.

In our study, $>90 \%$ of the participants demonstrated the poor nasal spray technique at baseline assessment. Such poor technique may be associated with poor disease control. Our intervention improved the participants demonstrating the correct technique to $84 \%$. The nasal spray use technique was poor that might be due to inadequate instruction provided at the time of dispensing or patients forgetting how to use it. The result is similar to the study 
Table 3 Association of Socio-Demographic Characteristic with the Effect of the Intervention

\begin{tabular}{|c|c|c|c|c|c|c|c|c|c|}
\hline \multirow[t]{2}{*}{ Variables } & \multirow[t]{2}{*}{ Category } & \multicolumn{4}{|c|}{ Pre-Intervention } & \multicolumn{4}{|c|}{ Post-Intervention } \\
\hline & & Poor & Moderate & Good & p-value & Poor & Moderate & Good & p-value \\
\hline Age (years) & $\begin{array}{l}18-35 \\
36-55 \\
\geq 55\end{array}$ & $\begin{array}{l}44 \\
23 \\
6\end{array}$ & $\begin{array}{l}5 \\
3 \\
0\end{array}$ & $\begin{array}{l}0 \\
0 \\
0\end{array}$ & 0.689 & $\begin{array}{l}2 \\
2 \\
2\end{array}$ & $\begin{array}{l}6 \\
1 \\
0\end{array}$ & $\begin{array}{l}41 \\
23 \\
4\end{array}$ & 0.078 \\
\hline Gender & $\begin{array}{l}\text { Male } \\
\text { Female }\end{array}$ & $\begin{array}{l}38 \\
35\end{array}$ & $\begin{array}{l}4 \\
4\end{array}$ & $\begin{array}{l}0 \\
0\end{array}$ & 0.912 & $\begin{array}{l}2 \\
4\end{array}$ & $\begin{array}{l}5 \\
2\end{array}$ & $\begin{array}{l}35 \\
33\end{array}$ & 0.386 \\
\hline Marital status & $\begin{array}{l}\text { Married } \\
\text { Unmarried }\end{array}$ & $\begin{array}{l}18 \\
55\end{array}$ & $\begin{array}{l}4 \\
4\end{array}$ & $\begin{array}{l}0 \\
0\end{array}$ & 0.126 & $\begin{array}{l}1 \\
5\end{array}$ & $\begin{array}{l}2 \\
5\end{array}$ & $\begin{array}{l}19 \\
49\end{array}$ & 0.834 \\
\hline Education & $\begin{array}{l}\text { Informal } \\
\text { Basic } \\
\text { Secondary } \\
\text { Undergraduate and above }\end{array}$ & $\begin{array}{l}5 \\
15 \\
31 \\
23\end{array}$ & $\begin{array}{l}0 \\
1 \\
6 \\
7\end{array}$ & $\begin{array}{l}0 \\
0 \\
0 \\
0\end{array}$ & $* 0.003$ I & $\begin{array}{l}1 \\
4 \\
2 \\
0\end{array}$ & $\begin{array}{l}2 \\
1 \\
5 \\
1\end{array}$ & $\begin{array}{l}2 \\
11 \\
24 \\
28\end{array}$ & $* 0.009$ \\
\hline Occupation & $\begin{array}{l}\text { House maker } \\
\text { Agriculture } \\
\text { Business } \\
\text { Government employ } \\
\text { Self employed } \\
\text { Teacher } \\
\text { Student } \\
\text { Labor }\end{array}$ & $\begin{array}{l}20 \\
14 \\
10 \\
4 \\
4 \\
9 \\
10 \\
2\end{array}$ & $\begin{array}{l}1 \\
0 \\
1 \\
2 \\
1 \\
1 \\
2 \\
0\end{array}$ & $\begin{array}{l}0 \\
0 \\
0 \\
0 \\
0 \\
0 \\
0 \\
0\end{array}$ & 0.4 & $\begin{array}{l}3 \\
1 \\
1 \\
0 \\
0 \\
0 \\
1 \\
0\end{array}$ & $\begin{array}{l}1 \\
3 \\
0 \\
1 \\
0 \\
1 \\
0 \\
1\end{array}$ & $\begin{array}{l}17 \\
10 \\
10 \\
5 \\
5 \\
9 \\
11 \\
1\end{array}$ & 0.46 \\
\hline
\end{tabular}

Note: *Significant at $\mathrm{p}<0.05$.

by Rollema et al on technique to administer INCS. ${ }^{15}$ In our study, shaking the spray and inhaling while spraying was performed by almost all the participants $(90.10 \%$ and $85.2 \%$, respectively). Only $79(69 \%)$ respondents inserted the tip of the spray correctly, ie, aiming laterally. A study done by Rollema et al and Benninger et al suggests that aiming the tip laterally reduces the potential of epistaxis. ${ }^{15,17}$ Only 19 (23.50\%) subjects blew their nose while in the study by Rollema et al, almost half of the patients (48\%) blew their nose. All the respondents missed Step 7 (bending the head between the knees immediately after application) and Step 8 (sitting up after a few seconds). This was because patients were not instructed about these steps though it was mentioned in the WHO checklist. Benninger evaluated this position; mecca position is the effective position though uncomfortable. ${ }^{17}$ Only $9(11.1 \%)$ respondents breathe out through the mouth. Not even one in ten $3(3.70 \%)$ respondents cleaned the tip after use. This shows that subjects had inadequate knowledge on cleaning and management of the spray.

After providing the intervention, the number of patients performing the steps correctly was increased by $50.27 \%$. After the immediate intervention, $96.3 \%$ of subjects blew their nose before administering the spray which decreases to $85.2 \%$ after the intervention. This may be because there was an improvement in their symptoms of nasal discharge. At the immediate intervention, all the subjects tilted their head while administering the spray. But at post-intervention, the percentage decreased to 97.50 . This might be because the patients forget the step or were not conscious of the importance of each step. The slight decrease in the percentage of subjects performing each step correctly at intervention maybe because they forget the step or they were not aware of each step. Though there is a slight decrease in the subjects performing each step correctly at post-intervention as compared to immediate intervention, there is a satisfactory improvement comparing to the pre-intervention.

In our study, two subjects had same score before and after intervention. There is no exact reason behind this. But it may be because they were not aware about the interventional program. In our study, education was significantly associated with the intervention. This may indicate that the educated subjects who receive the training had better possibility of demonstrating the correct nasal spray use technique.

The interventional programs help improving compliance and the interventions using pictorial aid are more 
beneficial for patients. ${ }^{18,19}$ In Nepal, the local manufacturers do not manufacture the INCS and hence patient information leaflets (PILs) are not available in the native language. So the leaflets in local language with a proper demonstration of the technique on the use of nasal sprays help patients understand the steps.

The study had some limitations. First, the impact of the intervention was evaluated only once and the study has not correlated the improvement of the technique with clinical outcomes. In the study, the patients were from a single center, which may affect the generalization of the finding. Besides these limitations, our study has assessed the current status of nasal spray use technique among the patients and evaluated the effect of training and educational intervention on the use of nasal spray.

\section{Conclusion}

The current nasal spray use technique was found to be inadequate among subjects. Pharmacist-led intervention on nasal spray use technique was effective which can significantly improve the correct use of the nasal spray. There was an association between education and the spray use technique. Though the intervention provided by the pharmacist was successful in improving the spray use technique, regular assessment and reinforcement of correct technique by health professionals are essential to improve the compliance and proper use. The leaflets with a proper demonstration of the technique on the use of the nasal spray in the native language help patient to understand the steps. Evaluation of the technique should be repeated by the pharmacists or doctors that will improve the proper use technique of the nasal spray, hence increasing the effectiveness of the therapy.

\section{Acknowledgments}

The authors would like to thank the patients and their caregivers, pharmacy practitioners and other health-care professionals for their participation and valuable support throughout the study.

\section{Disclosure}

The authors report no conflict of interest in this work.

\section{References}

1. Sheth K. Evaluating the safety of intranasal steroids in the treatment of allergic rhinitis. Allergy Asthma Clin Immunol. 2008;4(3):125-129. doi:10.1186/1710-1492-4-3-125
2. Mehuys E, Gevaert P, Brusselle G, et al. Self-medication in persistent rhinitis: overuse of decongestants in half of the patients. $J$ Allergy Clin Immunol Pract. 2014;2(3):313-319. doi:10.1016/j.jaip.20 14.01.009

3. Tran NP, Vickery J, Blaiss MS. Management of rhinitis: allergic and non-allergic. Allergy Asthma Immunol Res. 2011;3(3):148-156. doi:10.4168/aair.2011.3.3.148

4. Lenz D, Cardoso KS, Bitti ACR, Andrade TU. Evaluation of the use of topic nasal decongestants in university students from health sciences courses. Braz J Pharm Sci. 2011;47(4):761-766. doi:10.1590/S1984-82502011000400013

5. Bridgeman MB. Overcoming barriers to intranasal corticosteroid use in patients with uncontrolled allergic rhinitis. Integr Pharm Res Pract. 2017;6:109-119. doi:10.2147/IPRP.S129544

6. Hellings PW, Dobbels F, Denhaerynck K, Piessens M, Ceuppens JL, De Geest S. Explorative study on patient's perceived knowledge level, expectations, preferences and fear of side effects for treatment for allergic rhinitis. Clin Transl Allergy. 2012;2(1):1-8. doi:10.1186/ 2045-7022-2-9

7. Garlapati RR, Lee HP, Chong FH, Wang DY. Indicators for the correct usage of intranasal medications: a computational fluid dynamics study. Laryngoscope. 2009;119(10):1975-1982. doi:10.100 2/lary. 20660

8. Bateman ND, Whymark AD, Clifton NJ, Woolford TJ. A study of intranasal distribution of azelastine hydrochloride aqueous nasal spray with different spray techniques. Clin Otolaryngol. 2002;27:327-330. doi:10.1046/j.1365-2273.2002.00589.x

9. Rudmik L, Xu Y, Liu M, Bird C, Kukec E, Quan H. Utilization patterns of topical intranasal steroid therapy for chronic rhinosinusitis a canadian population-based analysis. JAMA Otolaryngol Head Neck Surg. 2016;142(11):1056-1062. doi:10.1001/jamaoto.2016.1110

10. Klossek JM, Neukirch F, Pribil C, et al. Prevalence of nasal polyposis in France: a cross-sectional, case-control study. Allergy Eur J Allergy Clin Immunol. 2005;60(2):233-237. doi:10.1111/j.1398-9995.20 05.00688.x

11. Benninger MS, Ahmad N, Marple BF. The safety of intranasal steroids. Otolaryngol Head Neck Surg. 2003;129(6):739-750. doi:10.1016/j.otohns.2003.10.001

12. Benninger MS. Epistaxis and its relationship to handedness with use of intranasal steroid spray. ENT-Ear Nose Throat J. 2008;87(8):2-4.

13. Haynes R, McDonald H, Garg A, Montague P. Interventions for helping patients to follow prescriptions for medications. Cochrane Database Syst Rev. 2003.

14. Ansari M, Rao BS, Koju R, Shakya R. Impact of pharmaceutical intervention on inhalation technique. Kathmandu Univ J Sci Eng Technol. 2005;1(1):1-10.

15. Rollema C, Van Roon EN, de Vries TW. Inadequate quality of administration of intranasal corticosteroid sprays. J Asthma Allergy. 2019;12:91-94. doi:10.2147/JAA.S189523

16. Chong SN, Chew FT. Epidemiology of allergic rhinitis and associated risk factors in Asia. World Allergy Organ J. 2018;11(1):17. doi:10.1186/s40413-018-0198-z

17. Benninger MS, Hadley JA, Osguthorpe JD, et al. Techniques of intranasal steroid use. Otolaryngol Head Neck Surg. 2004;130 (1):5-24. doi:10.1016/j.otohns.2003.10.007

18. Roter DL, Hall JA, Merisca R, Beth Nordstrom D, Svarstad B. Effectiveness of interventions to improve patient compliance: a meta-analysis. Med Care. 1998;36(8):21337802. doi:10.1097/ 00005650-199808000-00004

19. Katz MG, Kripalani S, Weiss BD. Use of pictorial aids in medication instructions: a review of the literature. Am J Health Pharm. 2006;63 (23):2391-2397. doi:10.2146/ajhp060162

20. Guide to good prescribing - a practical manual; 2000. Available from: http://helid.digicollection.org/en/d/Js2903e/7.3.5.html. Accessed June $6,2019$. 


\section{Publish your work in this journal}

Integrated Pharmacy Research and Practice is an international, peerreviewed, open access, online journal, publishing original research, reports, reviews and commentaries on all areas of academic and professional pharmacy practice. This journal aims to represent the academic output of pharmacists and pharmacy practice with particular focus on integrated care. All papers are carefully peer reviewed to ensure the highest standards as well as ensuring that we are informing and stimulating pharmaceutical professionals. The manuscript management system is completely online and includes a very quick and fair peer-review system, which is all easy to use. Visit http://www.dovepress.com/testimonials.php to read real quotes from published authors. 